Wright State University

CORE Scholar

2-1-1992

\title{
Electron-Paramagnetic-Resonance Study of GaAs Grown by Low- Temperature Molecular-Beam Epitaxy
}

\author{
H. J. Vonbardeleben \\ M. O. Manasreh \\ David C. Look \\ Wright State University - Main Campus, david.look@wright.edu \\ K. R. Evans \\ C. E. Stutz
}

Follow this and additional works at: https://corescholar.libraries.wright.edu/physics

Part of the Physics Commons

\section{Repository Citation}

Vonbardeleben, H. J., Manasreh, M. O., Look, D. C., Evans, K. R., \& Stutz, C. E. (1992). Electron-

Paramagnetic-Resonance Study of GaAs Grown by Low-Temperature Molecular-Beam Epitaxy. Physical Review B, 45 (7), 3372-3375.

https://corescholar.libraries.wright.edu/physics/190

This Article is brought to you for free and open access by the Physics at CORE Scholar. It has been accepted for inclusion in Physics Faculty Publications by an authorized administrator of CORE Scholar. For more information, please contact library-corescholar@wright.edu. 


\title{
Electron-paramagnetic-resonance study of GaAs grown by low-temperature molecular-beam epitaxy
}

\author{
H. J. von Bardeleben \\ Groupe de Physique des Solides, Centre National de la Recherche Scientifique, Université Paris VII, \\ 2 place Jussieu, 75251 Paris CEDEX 05, France \\ M. O. Manasreh \\ Electronic Technology Directorate (WL, ELRA), Wright Laboratory, Wright-Patterson Air Force Base, Dayton, Ohio $45433-6543$ \\ D. C. Look \\ University Research Center, Wright State University, Dayton, Ohio 45435 \\ K. R. Evans and C. E. Stutz \\ Electronic Technology Directorate (WL, ELRA), Wright Laboratory, Wright-Patterson Air Force Base, Dayton, Ohio $45433-6543$
}

(Received 30 May 1991)

\begin{abstract}
Electron-paramagnetic-resonance results demonstrate an arsenic-antisite related deep donor defect to be the dominant native defect in GaAs layers grown by low-temperature molecular-beam epitaxy (LTMBE). This defect is different from the EL2-related native arsenic-antisite defect. The thermalequilibrium concentration of $3 \times 10^{18} \mathrm{~cm}^{-3}$ ionized $\mathrm{As}_{\mathrm{Ga}}$ defects directly shows the additional presence of unidentified acceptor defects in the same concentration range. The defect distribution in GaAs grown by LTMBE is unstable under thermal annealing at $T \gtrsim 500^{\circ} \mathrm{C}$.
\end{abstract}

GaAs layers grown by low-temperature molecularbeam epitaxy (LTMBE) have recently been shown to have highly improved properties as buffer layers in both modulation-doped field-effect transistor (MODFET) and metal-semiconductor field-effect transistor (MESFET) devices as compared to conventionally grown $\left(T \simeq 600^{\circ} \mathrm{C}\right)$ GaAs layers. ${ }^{1}$ They eliminate backgating and reduce both the sidegating and the light sensitivity of these devices. The modifications of the electrical and optical properties of these undoped LTMBE layers are due to a drastic change in the native-defect concentrations. Whereas conventional layers are characterized by native defects in the $10^{14}-\mathrm{cm}^{-3}$ concentration range, ${ }^{2,3}$ results on layers grown at $200{ }^{\circ} \mathrm{C}$ indicate native defects at concentration higher than $10^{19} \mathrm{~cm}^{-3} .4,5$ Among them, only the arsenic-antisite has, to our knowledge, been identified. $^{4,6,7}$ In fact, arsenic-antisite defects have been studied before by magnetic-resonance techniques and one of the main results is that there is not just one arsenicantisite defect, but that at least, three different arsenicantisite-related defects can exist in GaAs; ${ }^{8-10}$ they are distinguished by their central hyperfine interactions and different excited states; ${ }^{11,12}$ their exact different local atomic configuration are unknown. We report in this paper electron-paramagnetic-resonance (EPR) results on the arsenic-antisite defect in LTMBE layers, and demonstrate that they are different from the EL2-related $\mathrm{As}_{\mathrm{Ga}}$ defect. We have further investigated the thermal stability of these defects in the $200-600^{\circ} \mathrm{C}$ temperature range. Our results demonstrate first a rearrangement of the local aiomic defert comfinguration at tempreationes as low as $400^{\circ} \mathrm{C}$. Further annealing at higher temperature $\left(T>450^{\circ} \mathrm{C}\right.$ ) then leads to a $90 \%$ annihilation of the $\mathrm{As}_{\mathrm{Ga}}$ defects. These results are extremely surprising when compared to those obtained for the $E L 2$-related $\mathrm{As}_{\mathrm{Ga}}$, for which a high thermal stability $\left(\gtrsim 950^{\circ} \mathrm{C}\right)$ in bulk liquidencapsulated Czochralski (LEC) samples has been reported. ${ }^{13}$

Recent Hall-effect measurements ${ }^{5}$ have also given a first insight into the electrical compensation in these LTMBE layers. Temperature-dependent Hall data were fitted with a high concentration $N_{D}$ of deep donors with a thermal ionization energy of $0.75 \mathrm{eV}$, as expected for EL2-like $\mathrm{As}_{\mathrm{Ga}}$ defects, but were also fitted with a low concentration of native acceptors $N_{A}$ with $N_{A} / N_{D} \sim 10^{-4}$. Our EPR results, which concern the singly ionized $\mathrm{As}_{\mathrm{Ga}}$ defect, are inconsistent with this model, as they indicate a native acceptor concentration in the $10^{18}-\mathrm{cm}^{-3}$ range. These differences will be discussed later.

The MBE layers used in this study were grown in a Varian 360 system under normal As-stabilized conditions at a growth rate of $0.8 \mu \mathrm{m} / \mathrm{h}$ at a temperature of $200^{\circ} \mathrm{C}$ on undoped semi-insulating GaAs substrates. The layer thickness was $15 \mu \mathrm{m}$. The EPR measurements were performed with an $X$-band spectrometer under both thermal equilibrium conditions and after various optical excitation. Absolute spin concentrations were determined with a NBS standard sample. Isochronal thermal annealings of the samples for $15 \mathrm{~min}$ in the $300-600^{\circ} \mathrm{C}$ temperature range were performed in an open furnace under a flowing argon stream between GaAs proximity wafers. Typical sample dimensions were $4 \times 8 \times 0.5 \mathrm{~mm}^{3}$. Similar samples had been previously studied by optical-absorption ${ }^{7}$ and Hall-etfect measurements.

When the samples were cooled under thermal equilibrium conditions to $4 \mathrm{~K}$, they showed one four-line EPR 
spectrum (Fig. 1), with the following parameters: isotropic $g$ factor $g=2.04 \pm 0.01$ and isotropic central hyperfine interaction $A=(866 \pm 13) \times 10^{-4} \mathrm{~cm}^{-1}$, with a nuclear spin $I=\frac{3}{2}$ of $100 \%$ isotopic abundance. This spectrum is attributed to an arsenic-antisite defect in the paramagnetic $1+$ charge state; by comparison with an $\mathrm{Al}_{2} \mathrm{O}_{3}: \mathrm{Cr}$ standard sample, the spin concentration is determined to $3 \times 10^{18} \mathrm{~cm}^{18} \mathrm{~cm}^{-3}$. The spectrum is well fitted by the Breit-Rabi formula ${ }^{14}$ [Fig. 1(b)], which indicates that no additional spectrum is observed under these conditions. To prove definitely that the EPR spectrum is exclusively originating from the MBE layer, on one sample this layer has been polished away. No EPR signal was observed at $4 \mathrm{~K}$ in the substrate without the layer. The $\mathrm{As}_{\mathrm{Ga}}$ spectrum is not saturated up to microwave powers of 100 $\mathrm{mW}$. The parameters of the spectrum do not vary with the microwave power $P$ for $0.2 \leq P \leq 100 \mathrm{~mW}$. The peak to peak linewidth is $400 \mathrm{G}$. The value of the central hyperfine interaction demonstrates in agreement with the short spin-lattice relaxation time at $4 \mathrm{~K}$ that the $A s_{\mathrm{Ga}}$ defect is different from the EL2-related one, which has an $A$ value of $(890 \pm 10) \times 10^{-4} \mathrm{~cm}^{-1,8}$ and due to long spin-lattice relaxation times can generally not be observed at $4 \mathrm{~K}$. However, its EPR parameters are close with those of the $\mathrm{As}_{\mathrm{Ga}}$ defect generated by electron irradiation in $n$-type GaAs. That defect, due to its formation mechanism ${ }^{9,10}$ as well as its simple magnetic circular dichroism spectrum ${ }^{11}$ had been attributed to the isolated $\mathrm{As}_{\mathrm{Ga}} ;{ }^{15}$ the EL2-related $\mathrm{As}_{\mathrm{Ga}}$ must then correspond to a different defect complex, as has been proposed before. ${ }^{16}$ A further fingerprint of the EL2-related $\mathrm{As}_{\mathrm{Ga}}$ defect is its metastability under near-infrared photoexcitation $(E \sim 1.2 \mathrm{eV})$. In agreement with previous results on the electron irradiated $\mathrm{As}_{\mathrm{Ga}},{ }^{15,17}$ the native $\mathrm{As}_{\mathrm{Ga}}$ defect in LTMBE GaAs is not photoquenchable at all. On the contrary, 1.2-eV photoexcitation leads to a persistent increase of up to $50 \%$ in the $\mathrm{As}_{\mathrm{Ga}}^{+}$concentration. We have further determined the spectral dependence of the optically induced $\mathrm{As}_{\mathrm{Ga}}^{+}$concentration increase in the

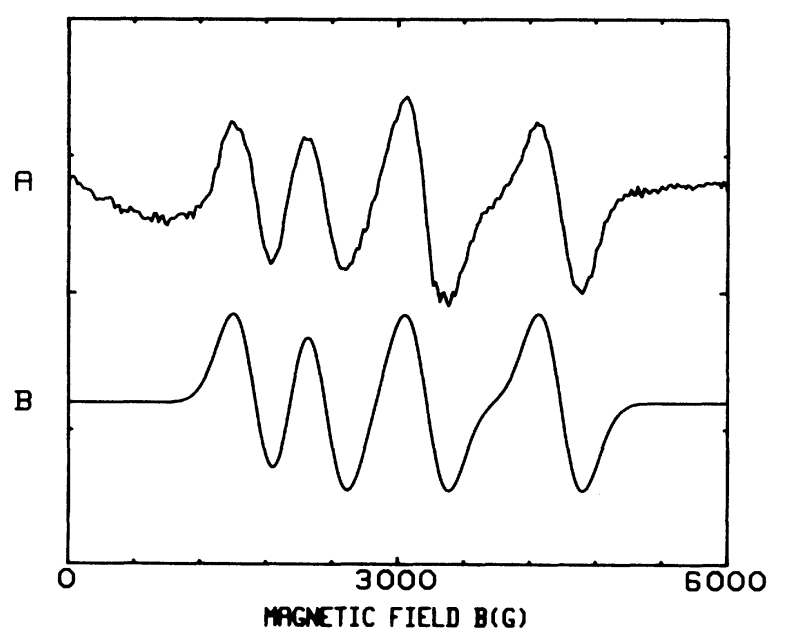

FIG. 1. EPR spectrum of a 15- $\mu$ m-thick LTMBE GaAs layer at $T=4 \mathrm{~K}$ : (a) experimental spectrum; (b) simulated $\mathrm{As}_{\mathrm{Ga}}^{+}$spectrum with $g=2.04, A=866 \times 10^{-4} \mathrm{~cm}^{-1} \Delta B_{p p}=400 \mathrm{G}$.
0.5-1.5-eV energy range: from a threshold energy $E=0.6 \mathrm{eV}$, its concentration is increased for all photon energies up to $1.5 \mathrm{eV}$.

The optically induced increase in the $\mathrm{As}_{\mathrm{Ga}}^{+}$concentration must be due to photoionization of either $\mathrm{As}_{\mathrm{Ga}}^{0}$ to the conduction band or $\mathrm{As}_{\mathrm{Ga}}^{2+}$ to the valence band. From previous optical-absorption studies on similar samples grown under identical conditions, we know that most of the $\mathrm{As}_{\mathrm{Ga}}$ defects are present in the neutral charge state under thermal equilibrium condition $\left(N_{D}^{0} \sim 3 \times 19^{19} \mathrm{~cm}^{-3}\right) ;^{7}$ thus the Fermi level is blocked in these samples on the $0 /+$ level of the $\mathrm{As}_{\mathrm{Ga}}$ defect. In this case, the dominant photoionization process for photon energies of $\gtrsim 0.6 \mathrm{eV}$ will be $\mathrm{As}_{\mathrm{Ga}}^{0} \rightarrow A s_{\mathrm{Ga}}^{+}+e^{-}$, where the free electron is trapped on the electron traps. The position of the $0 /+$ level in the gap has been shown before for the electronirradiation-induced $\mathrm{As}_{\mathrm{Ga}}$ to be shifted to the conduction band $^{16}$ as compared to the $E L 2$-related $0 /+$ level, which is at $E_{c}-0.76 \mathrm{eV}$. The photoionization threshold of 0.6 eV observed in our LTMBE samples confirms these results and situates the $0 /+\mathrm{As}_{\mathrm{Ga}}$ level in this case at $\lesssim E_{c}-0.6 \mathrm{eV}$. However, it should be noted that the Hall-effect donor is at $E_{c}-0.75 \mathrm{eV} .^{7}$

Our EPR results demonstrate further the presence of both additional donor and acceptor defects in the $10^{18}$. $\mathrm{cm}^{-3}$ concentration range in these low-temperaturegrown layers. From the $\mathrm{As}_{\mathrm{Ga}}^{+}$concentration of $3 \times 10^{18}$ $\mathrm{cm}^{-3}$ in thermal equilibrium, a lower limit for the total acceptor concentration below the Fermi level must be $3 \times 10^{18} \mathrm{~cm}^{-3}$. This value apparently disagrees with the electrical compensation model based on Hall-effect measurements, where from a fitting procedure an acceptor concentration of $7 \times 10^{-14} \mathrm{~cm}^{-3}$ had been proposed; these issues are discussed below. As a result of the expected low degree of contamination during the $\mathrm{MBE}$ growth process, which for $\sim 600^{\circ} \mathrm{C}$ growth temperatures gives rise to extrinsic acceptor $(\mathrm{C}, \mathrm{Zn})$ contaminations in the $10^{14}-10^{15}-\mathrm{cm}^{-3}$ range, the native acceptor compensating the $\mathrm{As}_{\mathrm{Ga}}$ donor is expected to be of intrinsic nature. The $\mathrm{Ga}_{\mathrm{As}}$ and the $\mathrm{V}_{\mathrm{Ga}}$ seem to be the most probable candidates.

The optically induced photoionization of $\mathrm{As}_{\mathrm{Ga}}^{0}$, which is stable at $4 \mathrm{~K}$, shows the additional presence of shallow electron traps in the $10^{18}-\mathrm{cm}^{-3}$ concentration range. In agreement with a previous observation, ${ }^{4,6}$ we find two partial thermal annealing stages for this process at 50 and $100 \mathrm{~K}$ corresponding to the thermally activated reemission of the photocaptured electrons from these donors; they are shallower than the $\mathrm{As}_{\mathrm{Ga}}^{0 /+}$ level; their thermal ionization energy can be roughly estimated from the thermal annealing stages to $\sim 100 \mathrm{meV}$. The previous attribution ${ }^{4,6}$ of the photoionization process to the valence-band- $\mathrm{As}_{\mathrm{Ga}}^{2+}$ transition and the corresponding thermal annealing steps at 50 and $100 \mathrm{~K}$ to hole emission from acceptor states does not apply in our case on the basis of our combined optical-absorption and EPR results.

We have further studied the thermal stability of the $\mathrm{As}_{\mathrm{Ga}}$ defects for annealings in the $300-600^{\circ} \mathrm{C}$ temperature range. From the optical-absorption studies ${ }^{7}$ as well 
as the Hall-effect results ${ }^{5}$ a drastic change in the defect concentration after annealing at temperatures higher than $450^{\circ} \mathrm{C}$ has been reported. Further, the lattice parameter of the LTMBE material, which shows an increase of $\sim 0.1 \%$ as compared to the LEC-grown substrate material, has also been reported to decrease after annealing at $450^{\circ} \mathrm{C}$ to that of the substrate material..$^{4,6}$ Our EPR results of 15 -min isochronal anneal are given in Table I and Fig. 2: after a $300^{\circ} \mathrm{C}$ anneal, the thermal equilibrium values of the $\mathrm{As}_{\mathrm{Ga}}^{+}$defect-concentration and EPR parameters - are unchanged. The additional $400^{\circ} \mathrm{C}$ anneal increases the $\mathrm{As}_{\mathrm{Ga}}^{+}$concentration by $\sim 10 \%$; but now the hyperfine interaction constant of the totality of the $\mathrm{As}_{\mathrm{Ga}}^{+}$ions has changed to $877 \times 10^{-4} \mathrm{~cm}^{-1}$. Nevertheless, a low-temperature photoexcitation shows still no metastability of this defect. The anneal at $500^{\circ} \mathrm{C}$ then reduces the $\mathrm{As}_{\mathrm{Ga}}^{+}$concentration by a factor of 6 and the $600^{\circ} \mathrm{C}$ anneal by an additional factor of 4 without further change in the hyperfine interaction.

Since $\left[\mathrm{As}_{\mathrm{Ga}}^{+}\right] \simeq N_{A}$, it follows that $N_{A}$ decreases from $3 \times 10^{18}$ to $1.5 \times 10^{17} \mathrm{~cm}^{-3}$ after a $600^{\circ} \mathrm{C}$ anneal. However, the Hall-effect ${ }^{5}$ and absorption ${ }^{7}$ results show that $\left[\mathrm{As}_{\mathrm{Ga}}\right]$ itself decreases by about a factor of 10-20. The data from the three different experiments correlate well as a function of annealing temperature, as shown in Fig. 2. Note that the decrease in $N_{A}$ is in qualitative agreement with the results of Ref. 4 . Note also that a similar low thermal stability of the EL2-related $\mathrm{As}_{\mathrm{Ga}}$ defect has been reported before, ${ }^{18}$ but only for the near-surface regions (a few $\mu \mathrm{m}$ ).

We now return to the apparent discrepancy between the EPR results reported here, which are consistent with an acceptor concentration of $N_{A}$ of $3 \times 10^{18} \mathrm{~cm}^{-3}$ in unannealed material, and the temperature-dependent Hall-effect results, ${ }^{5}$ which are best fitted with

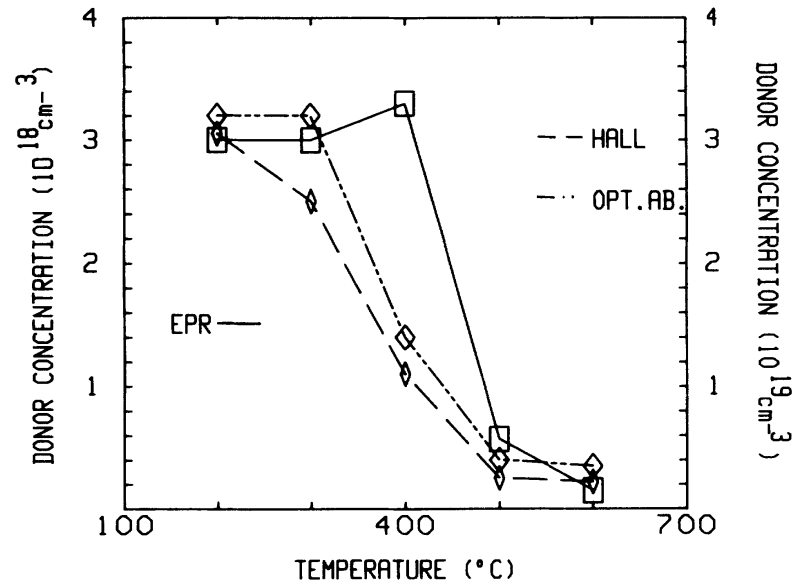

FIG. 2. Variation of the ionized $\mathrm{As}_{\mathrm{Ga}}^{+}$concentration ( - ) as well as the neutral $\mathrm{As}_{\mathrm{Ga}}^{0}$ concentration (-.-.-.) (after Ref. 7) and the total donor concentration (- - ) (after Ref. 5) as a function of isochronal annealing.

perature, then $N_{D} \sim 2 \times 10^{21} \mathrm{~cm}^{-3}$, which is clearly impossible and also disagrees strongly with the $N_{D}$ values $\left(\sim 3 \times 10^{18} \mathrm{~cm}^{-3}\right)$ measured by both absorption ${ }^{7}$ and Hall effect ${ }^{5}$ in annealed samples. There are two possible resolutions to this discrepancy. The first involves the fact that the majority of $200^{\circ} \mathrm{C}$, MBE-grown GaAs layers are known to contain large concentrations of pyramidalshaped defects. ${ }^{19}$ It is quite possible that such defects could be decorated with acceptors (perhaps $V_{\mathrm{Ga}}$ ) close to the valence band, and thus induce a charge transfer $\left(\mathrm{As}_{\mathrm{Ga}}^{0}+V_{\mathrm{Ga}}^{0} \rightarrow \mathrm{As}_{\mathrm{Ga}}^{+}+V_{\mathrm{Ga}}^{-}\right)$for $\mathrm{As}_{\mathrm{Ga}}$ centers in the vicinity of the pyramidal defects. The EPR results could be explained if about $10 \%$ of the total $\mathrm{As}_{\mathrm{Ga}}\left(3 \times 10^{19} \mathrm{~cm}^{-3}\right.$ in unannealed material) participated in the charge exchange. The Hall and absorption experiments would be 
donor defects in the $10^{18} \mathrm{~cm}^{-3}$ range have been found. The $\mathrm{As}_{\mathrm{Ga}}$ defect is unstable for $450^{\circ} \mathrm{C}$ thermal annealing; the unexpected low thermal stability of the $\mathrm{As}_{\mathrm{Ga}}$ defects in LTMBE GaAs - contrary to the EL2-related $\mathrm{As}_{\mathrm{Ga}}$ de- fect in melt-grown GaAs - leads to the previously report$\mathrm{ed}^{5,7}$ modification of the electrical and optical properties of this material after thermal annealing in this temperature range.
${ }^{1}$ F. W. Smith, A. R. Calawa, C. L. Chen, M. J. Maufra, and L. J. Mahoney, IEEE Electron Device Letters EDL-9, 77 (1980).

${ }^{2}$ D. V. Lang, A. Y. Cho, A. C. Gossard, M. Ilegems, and W. Weigman, J. Appl. Phys. 47, 2558 (1976).

${ }^{3}$ V. Smid, P. Hubik, A. Bosacchi, S. Franchi, E. Gambia, and L. Vanzetti, in Materials Science Forum, edited by G. Ferenczi (Trans Tech, Aedermannsdorf, 1989), Vol. 38, p. 135.

${ }^{4}$ M. Kaminska, Z. Lilienthal-Weber, E. R. Weber, T. George, J. K. Kortright, F. W. Smith, B. Y. Tsaur, and A. R. Calawa, Appl. Phys. Lett. 54, 1881 (1989).

${ }^{5}$ D. C. Look, D. C. Walters, M. O. Manasreh, J. R. Sizelove, C. E. Stutz, and K. R. Evans, Phys. Rev. B 42, 3578 (1990).

${ }^{6}$ M. Kaminska, E. R. Weber, Z. Lilienthal-Weber, R. Leon, and Z. U. Rek, J. Vac. Sci. Technol. B 7, 710 (1989).

${ }^{7}$ M. O. Manasreh, D. C. Look, K. R. Evans, and C. E. Stutz, Phys. Rev. B 41, 10272 (1990).

${ }^{8}$ R. J. Wagner, J. T. Krebs, G. M. Strauss, and A. M. White, Solid State Commun. 36, 15 (1980).

${ }^{9}$ H. J. von Bardeleben, A. Miret, H. Lim, and J. C. Bourgoin, J. Phys. C 20, 1353 (1987).

${ }^{10}$ H. J. von Bardeleben, J. C. Bourgoin, and A. Miret, Phys. Rev. B 34, 1360 (1986).

${ }^{11}$ B. K. Meyer, D. M. Hofmann, J. R. Niklas, and J. M. Spaeth,
Phys. Rev. B 30, 1332 (1987).

${ }^{12}$ J. M. Spaeth, K. Krambock, and D. M. Hofmann, in Proceedings of the 19th International Conference of the Physics of Semiconductors, Thessaloniki, 1990, edited by E. M. Anastassakis and J. D. Joannopoulos (World Scientific, Singapore, 1990), Vol. 1, p. 441.

${ }^{13}$ U. Kaufmann, J. Windscheif, M. Baumler, J. Schneider, and F. Kohl, in Semi-Insulating III-V Materials, edited by D. C. Look and J. S. Blakemore (Shiva, Nautwich, 1984), p. 246.

${ }^{14}$ G. Breit and I. I. Rabi, Phys. Rev. 38, 2082 (1931).

${ }^{15}$ H. J. von Bardeleben, J. C. Bourgoin, and D. Stievenard, in Materials Science Forum (Ref. 3), Vol. 38, p. 97.

${ }^{16}$ H. J. von Bardeleben, D. Stievenard, D. Deresmes, A. Huber, and J. C. Bourgoin, Phys. Rev. B 34, 7192 (1986).

${ }^{17}$ N. K. Goswami, R. C. Newman, and J. E. Whitehouse, Solid State Commun. 40, 473 (1981).

${ }^{18}$ G. M. Martin and S. Makram-Ebeid, in Deep Centers in Semiconductors: A Study of the Art Approach, edited by S. Pantelides (Gordon and Breach, New York, 1986), p. 399.

${ }^{19}$ Z. Lilienthal-Weber, F. Smith, and A. R. Calawa (unpublished).

${ }^{20}$ H. J. von Bardeleben, J. C. Bourgoin, and D. Stievenard, Appl. Phys. Lett. 53, 1083 (1988). 